\title{
Activated Carbons Derived from Teak Sawdust-Hydrochars for Efficient Removal of Methylene Blue, Copper, and Cadmium from Aqueous Solution
}

\author{
Hai Duy Nguyen ${ }^{1}$, Hai Nguyen Tran ${ }^{2}{ }^{-}$, Huan-Ping Chao ${ }^{3, *}$ and Chu-Ching Lin ${ }^{1, *}$ \\ 1 Institute of Environmental Engineering, National Central University, Taoyuan 32001, Taiwan; \\ nguyenduyhai@tuaf.edu.vn \\ 2 Institute of Fundamental and Applied Sciences, Duy Tan University, Ho Chi Minh City 700000, Vietnam; \\ trannguyenhai2512@gmail.com \\ 3 Department of Environmental Engineering, Chung Yuan Christian University, Taoyuan 32023, Taiwan \\ * Correspondence: hpchao@cycu.edu.tw (H.-P.C.); chuching@ncu.edu.tw (C.-C.L.); \\ Tel.: +886-3-265-4914 (H.-P.C.); +886-3-422-7151 (ext. 34654) (C.-C.L.)
}

Received: 11 November 2019; Accepted: 1 December 2019; Published: 6 December 2019

\begin{abstract}
Recycling materials from waste has been considered one of the essential principles in the context of sustainable development. In this study, we used teak sawdust as the feedstock material to synthesize activated carbon (AC) samples and evaluated the application of these ACs in the adsorption of methylene blue (MB), $\mathrm{Cd}(\mathrm{II})$, and $\mathrm{Cu}(\mathrm{II})$. The sawdust was carbonized by a hydrothermal process, followed by chemical activation using $\mathrm{K}_{2} \mathrm{CO}_{3}$ or $\mathrm{ZnCl}_{2}$ in various weight ratios. The AC samples produced were characterized by scanning electron microscopy, Brunauer-Emmett-Teller surface area analysis, Fourier-transform infrared spectroscopy, X-ray photon spectroscopy, and mass titration of acidic groups. The characterization results showed that the ACs did possess a high surface area and rich oxygen-containing functional groups. The adsorptive amounts of $\mathrm{MB}, \mathrm{Cd}(\mathrm{II})$, and $\mathrm{Cu}(\mathrm{II})$ on ACs approximately increased with the concentration of the activating agent: when the weight ratio of the carbonaceous material to $\mathrm{ZnCl}_{2}$ reached 1.75, the maximum adsorption capacities for $\mathrm{MB}$, $\mathrm{Cd}(\mathrm{II})$, and $\mathrm{Cu}$ (II) were achieved, and the values were 614,208 , and $182 \mathrm{mg} / \mathrm{g}$, respectively. The level of oxygen-containing functional groups was identified as an important factor in determining the adsorptive amounts. While the electrostatic force was the primary pathway that led to the adsorption of the tested contaminants onto the AC, the complexation reaction was a vital mechanism responsible for the adsorptive interaction between $\mathrm{ACs}$ and $\mathrm{Cu}(\mathrm{II})$. The high adsorption capacity of the synthetic $\mathrm{ACs}$ for $\mathrm{MB}, \mathrm{Cd}(\mathrm{II})$, and $\mathrm{Cu}(\mathrm{II})$ demonstrated in this study points out the potential application of biomass-residue-based adsorbents prepared via a coupled hydrothermal carbonization/chemical activation process in wastewater treatment.
\end{abstract}

Keywords: activated carbons; sawdust-hydrochars; dyes; heavy metals; adsorption mechanism

\section{Highlights}

- $\quad$ The activated carbon samples were synthesized through a two-step process.

- The hydrothermal carbonization resulted in rich oxygen-containing functional groups.

- $\quad$ The activating agents were used with different weight ratios to synthesize the new adsorbents.

- Heavy metals and dyes were used as the adsorbates to examine the adsorption capacity.

- $\quad$ The potential adsorption mechanisms were discussed in depth. 


\begin{tabular}{cc}
\hline & Nomenclature of Synthesized Activated Carbon \\
\hline WAC & Only high-temperature calcination without activation process \\
ACZ1075 & Weight ratio of $\mathrm{ZnCl}_{2}$ to $\mathrm{HTC}=0.75: 1.0$ \\
ACZ1100 & Weight ratio of $\mathrm{ZnCl}_{2}$ to $\mathrm{HTC}=1.0: 1.0$ \\
ACZ1125 & Weight ratio of $\mathrm{ZnCl}_{2}$ to $\mathrm{HTC}=1.25: 1.0$ \\
ACZ1175 & Weight ratio of $\mathrm{ZnCl}_{2}$ to $\mathrm{HTC}=1.75: 1.0$ \\
ACZ1200 & Weight ratio of $\mathrm{ZnCl}_{2}$ to $\mathrm{HTC}=2.0: 1.0$ \\
ACK1075 & Weight ratio of $\mathrm{K}_{2} \mathrm{CO}_{3}$ to $\mathrm{HTC}=0.75: 1.0$ \\
ACK1100 & Weight ratio of $\mathrm{K}_{2} \mathrm{CO}_{3}$ to $\mathrm{HTC}=1.0: 1.0$ \\
ACK1125 & Weight ratio of $\mathrm{K}_{2} \mathrm{CO}_{3}$ to $\mathrm{HTC}=1.25: 1.0$ \\
ACK1175 & Weight ratio of $\mathrm{K}_{2} \mathrm{CO}_{3}$ to $\mathrm{HTC}=1.75: 1.0$ \\
ACK1200 & Weight ratio of $\mathrm{K}_{2} \mathrm{CO}_{3}$ to $\mathrm{HTC}=2.0: 1.0$ \\
\hline
\end{tabular}

\section{Introduction}

Water contamination has become an important issue in recent years, especially in developing countries such as Vietnam. Biodegradation is the most common method for removing contaminants from water bodies. However, some contaminants, such as heavy metal ions and high-molecular-weight dyes, cannot be treated through biodegradation. Hence, a number of methods need to be developed for the removal of these contaminants [1-4]. Precipitation or ion exchange is commonly used to remove heavy metal ions from wastewater or water. Photocatalysis and advanced oxidation processes can be used to decompose dyes [5-8]. Although the abovementioned methods can effectively remove contaminants, many investigators have sought some simpler and lower-cost processes [9]. Adsorption is a process that is often used to remove various kinds of contaminants from water or wastewater [10-13]. Adsorbents with high adsorption capacities can lower the costs of water and wastewater treatments.

Activated carbon $(\mathrm{AC})$ has been widely used to adsorb organic and inorganic contaminants. This is because $\mathrm{AC}$ possesses a large specific surface area $\left(S_{\mathrm{BET}}\right)$ and high pore volume. Organic compounds can be adsorbed onto the surface of AC owing to the influence of van der Waals forces or through other mechanisms $[14,15]$. Following physical activation, commercial AC exhibits only low adsorption capacities for heavy metal ions [16]. When AC is activated via a chemical process, it can possess relatively higher adsorption capacities for heavy metal ions. A number of investigators have studied the ability of carbonaceous materials to adsorb heavy metal ions and dyes [17-21]. However, these adsorption mechanisms have not been discussed in depth.

The synthesis of AC is carried out in two steps: carbonization and activation. Carbonization has been previously applied to calcine agricultural wastes in oxygen-free environments [22,23]. However, a high carbonization temperature might reduce the amount of surface functionalities, such as the phenolic and carboxylic groups [3]. The conditions for the adsorption of cationic contaminants onto the adsorbent become unfavorable. Therefore, a new process of carbonization has been developed recently [24-26]. In this process, agricultural wastes are carbonized through a hydrothermal process, and the hydrothermal carbon products are subsequently applied to synthesize AC by chemical activation [16]. This process of carbonization can maintain the richness of surface functional groups, such as phenolic, lactonic, and carboxylic, on the carbonaceous materials. As the amount of surface functional groups is a critical factor in determining the adsorption capacities of carbonaceous materials for heavy metal ions, synthesized AC samples can be expected to possess high adsorption capacities for cationic contaminants.

In this study, sawdust from teak (Tectona grandis), which is rich in lignocellulose, was used as the raw material to prepare AC. This material is the waste of furniture-manufacturing factories, and to the best of our knowledge, discussion of its use in AC synthesis is still limited in the literature. To further improve the methylene blue (MB) and heavy metal species (including $\mathrm{Cu}$ (II) and $\mathrm{Cd}(\mathrm{II})$ ) sorption efficiency of $\mathrm{AC}$, the hydrothermal method of carbonization was selected, and $\mathrm{K}_{2} \mathrm{CO}_{3}$ and $\mathrm{ZnCl}_{2}$ were selected as the activating agents. The synthesized $\mathrm{AC}$ samples were characterized 
using Fourier-transform infrared spectroscopy (FTIR), scanning electron microscopy (SEM), X-ray photoelectron spectroscopy (XPS), and specific surface area and porosity analysis. The acidic functional groups on the surfaces of the AC samples were determined by the common Boehm titration method. The AC samples were used to adsorb dissolved copper and cadmium species, as well as the cationic dye MB. The adsorption capacities of the adsorbents under various conditions of activation were estimated. The potential adsorption mechanisms were evaluated by analyzing the adsorption capacities and surface properties of the adsorbents. The results obtained can be used as references for the treatment of water or wastewater.

\section{Materials and Methods}

\subsection{Chemicals and Activated Carbon Preparation}

All chemicals were of analytical grade and were directly used without further purification. $\mathrm{K}_{2} \mathrm{CO}_{3}$ was purchased from J. T. Baker. The other chemicals (i.e., $\mathrm{MB}, \mathrm{Cu}\left(\mathrm{NO}_{3}\right)_{2}, \mathrm{Cd}\left(\mathrm{NO}_{3}\right)_{2}$, and $\mathrm{ZnCl}_{2}$ ) were purchased from Sigma-Aldrich, Merck KGaA, Darmstadt, Germany. The teak (T. grandis) sawdust was obtained from a furniture factory in Taiwan. It was washed first with tap water to remove any adherent dirt and then with deionized distilled water at least twice. The sawdust was then ground and sieved using a 20-mesh screen. It was then placed in an oven at $80{ }^{\circ} \mathrm{C}$ for $24 \mathrm{~h}$ to obtain the dry samples. For the process of carbonization, $10 \mathrm{~g}$ of the sawdust sample was added into a beaker containing $120 \mathrm{~mL}$ of deionized distilled water. The mixture was transferred into a stainless Teflon-lined autoclave, which was placed in an oven at $190^{\circ} \mathrm{C}$ for $24 \mathrm{~h}$. The sample produced through hydrothermal carbonization (HTC) process was designated as sawdust-hydrochar. The precipitate was separated by filtration, washed repeatedly with deionized distilled water, and then dried in an oven at $105^{\circ} \mathrm{C}$. The sawdust-hydrochar samples obtained were stored in glass bottles until use.

The sawdust-hydrochar samples were activated using $\mathrm{K}_{2} \mathrm{CO}_{3}$ or $\mathrm{ZnCl}_{2}$ in various weight ratios $(0.75,1.0,1.25,1.75$, and 2.0$)$ of the activating agent to the sample. The hydrochar samples were impregnated in $100 \mathrm{~mL}$ solutions of the activating agents in the abovementioned weight ratios at $50^{\circ} \mathrm{C}$ for $30 \mathrm{~min}$. The solutions were dried in an oven at $105^{\circ} \mathrm{C}$. The dried samples were placed in the oven at $800{ }^{\circ} \mathrm{C}$ for $4 \mathrm{~h}$ to conclude the process of activation. The products were allowed to cool to room temperature and then were washed with deionized distilled water until their $\mathrm{pH}$ values were approximately 7.0. The products were dried in an oven overnight at $50^{\circ} \mathrm{C}$, and the $\mathrm{AC}$ samples were thus synthesized (Figure 1).

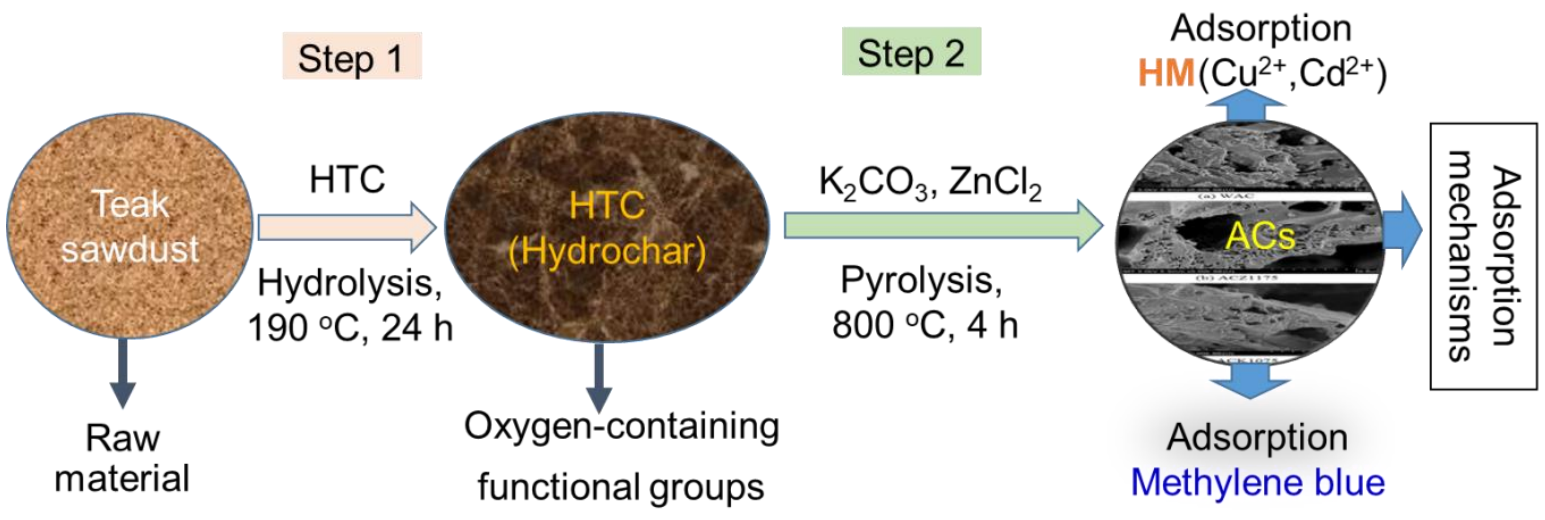

Figure 1. Schematic illustration of the preparation procedure for the activated carbon (AC) samples.

\subsection{Sorbent Characterization}

The surface properties of the synthesized adsorbents were determined using suitable instruments. An SEM (Hitachi S-3000N, Hitachi Scientific Instruments, Tokyo, Japan)was used to determine the morphologies of the adsorbents. The surface textures, including the values of $S_{\mathrm{BET}}$ and pore volume, 
were determined using the nitrogen adsorption/desorption isotherms (Micromeritics ASAP 2020 sorptometer, Micromeritics Instrument Corp., Chiba, Japan)at $77 \mathrm{~K}$. The surface area and volume of the micropores were calculated using the t-plot method (Jura-Harkins equation). The surface functional groups on the adsorbents were analyzed through FTIR spectroscopy (PerkinElmer Model 1600, Perkins Elmer Inc., Greenville, SC, USA) in the range of $400-4000 \mathrm{~cm}^{-1}$. An XPS (Thermo Fisher Scientific K-Alpha, the Thermo Scientific Inc., Waltham, MA, USA) was used to measure the elemental compositions. As functional groups are a critical factor in determining the adsorptive amount of the contaminants tested, the oxygen-containing functional groups (OFGs) were quantified using the Boehm titration method $[27,28]$.

\subsection{Sorption Experiment and Data Analysis}

To avoid adsorption interference, each adsorption experiment was conducted using a single adsorbate. Stock solutions of $1000 \mathrm{mg} \mathrm{Cu} / \mathrm{L}$ (using $\mathrm{Cu}\left(\mathrm{NO}_{3}\right)_{2} \cdot 3 \mathrm{H}_{2} \mathrm{O}$ ), $1000 \mathrm{mg} \mathrm{Cd} / \mathrm{L}$ (using $\mathrm{Cd}\left(\mathrm{NO}_{3}\right)_{2} \cdot 4 \mathrm{H}_{2} \mathrm{O}$ ), and $1000 \mathrm{mg} \mathrm{MB} / \mathrm{L}$ were prepared in distilled water. Approximately $0.1 \mathrm{~g}$ of the adsorbate was added to a Teflon centrifuge tube containing $50 \mathrm{~mL}$ of a solution of $\mathrm{pH} 5$ with the contaminant concentration in the range of $50-900 \mathrm{mg} / \mathrm{L}$. Three kinds of synthetic AC samples were used to adsorb MB, Cd(II), and $\mathrm{Cu}$ (II) at a fixed $\mathrm{pH}$ value of 5.0. The initial $\mathrm{pH}$ of the solution was adjusted to $5.0 \pm 0.1$ by $0.1 \mathrm{M} \mathrm{NaOH}$ and $\mathrm{HCl}$ solution. The centrifuge tubes were placed in a reciprocating shaker at $150 \mathrm{rpm}$ and $25^{\circ} \mathrm{C}$ and equilibrated for $24 \mathrm{~h}$. After the process, the solution was filtered with a $0.45 \mu \mathrm{m}$ filter. Next, copper and cadmium were analyzed using atomic absorption spectrometry (Avanta/AAS, GBC). MB was measured using a spectrophotometer (Genesys 10S UV-VIS, Thermo Fisher Scientific, Madison, WI, USA) through a colorimetric method at the wavelength of $665 \mathrm{~nm}$.

The Langmuir equation [29] was used to estimate the maximum adsorption capacities and can be expressed as follows in Equation (1):

$$
Q=\frac{x}{m}=\frac{K_{\mathrm{L}} b C}{1+K_{\mathrm{L}} C}
$$

where $Q$ is the maximum adsorptive amount of the contaminant for a given adsorbent $(\mathrm{mg} / \mathrm{g}$ or $\mathrm{mmol} / \mathrm{g}$ ), $x$ is the amount of contaminant adsorbed onto the adsorbent ( $\mathrm{mg}$ or $\mathrm{mmol}$ ), $m$ is the adsorbent weight $(\mathrm{g}), C$ is the equilibrium concentration $(\mathrm{mg} / \mathrm{L}$ or $\mathrm{mmol} / \mathrm{L})$ of the adsorbate in the solution, $K_{\mathrm{L}}$ is the equilibrium constant in the Langmuir equation $(\mathrm{L} / \mathrm{mg}$ or $\mathrm{L} / \mathrm{mmol})$, and $b$ is the maximum adsorption capacity $(\mathrm{mg} / \mathrm{g}$ or $\mathrm{mmol} / \mathrm{g})$.

\section{Results and Discussion}

\subsection{Characteristics of Sorbent Materials}

Figure 2 shows the SEM images of three representative AC samples: WAC, ACK1075, and ACZ1175. These samples were chosen because ACK1075 and ACZ1175 exhibited higher adsorptive amounts than the other $\mathrm{AC}$ samples activated using $\mathrm{K}_{2} \mathrm{CO}_{3}$ and $\mathrm{ZnCl}_{2}$, respectively. The SEM micrograph results indicate that their structures were not homogeneous. Notably, WAC displayed fragment shapes, whereas ACK1075 and ACZ1175 showed a rugged surface with a rather large pore. Moreover, the carbonaceous materials exhibited their relatively porous characteristics. These properties are close to those of other ACs synthesized through chemical activation $[30,31]$. The results demonstrated that the synthesized AC samples could possess comparatively high $S_{\mathrm{BET}}$ values to adsorb contaminants through the mechanism of van der Waals forces and pore filling. Based on the abovementioned results, all the AC samples synthesized through various activation processes in this study can be regarded as porous carbonaceous materials. 


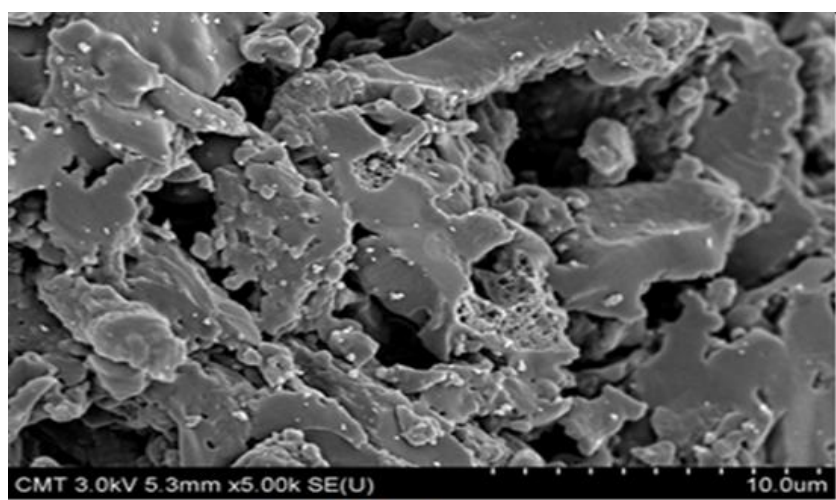

(a) WAC

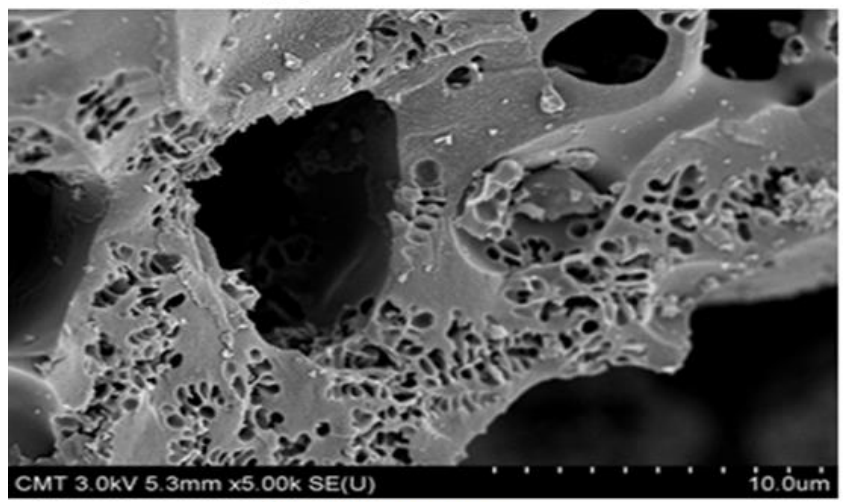

(b) $\mathrm{ACZ} 1175$

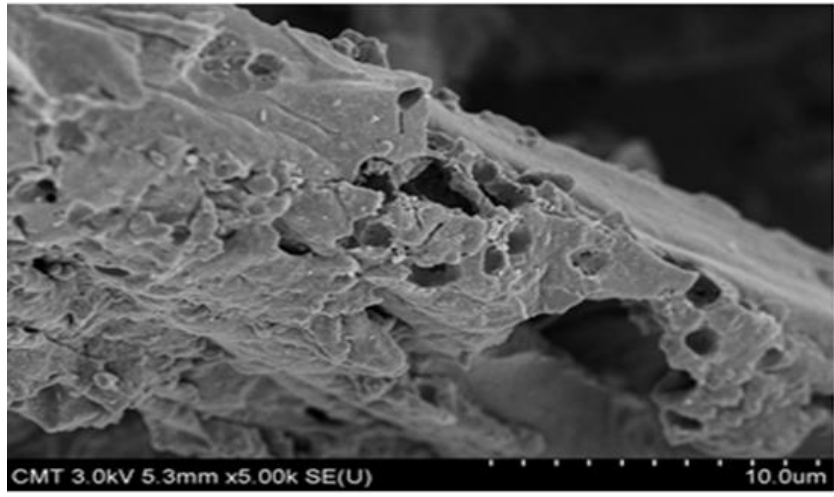

(c) ACK 1075

Figure 2. SEM images of (a) WAC, (b) ACZ1175, and (c) ACK1075.

To understand the pore characteristics, a nitrogen adsorption/desorption analyzer was used to measure the values of $S_{\mathrm{BET}}$, pore volume, and average pore size of the AC samples selected. Table 1 lists the measured values for WAC, ACK1075, and ACZ1175. WAC was synthesized through high-temperature calcination alone without activation. Thus, WAC possessed a relatively lower $S_{\mathrm{BET}}$ than the two activated carbon samples (ACK1075 and ACZ1175). Activation using $\mathrm{K}_{2} \mathrm{CO}_{3}$ and $\mathrm{ZnCl}_{2}$ significantly enhanced the $S_{\mathrm{BET}}$ values of the AC samples. Based on their average pore size, WAC and ACK1075 were classified as micropores (pore size $<2 \mathrm{~nm}$ ), while ACZ1175 was classified as a mesopore $(2 \mathrm{~nm}<$ pore size $<50 \mathrm{~nm})$. Although the AC samples produced possessed high $S_{\mathrm{BET}}$, their adsorption capacities for contaminants such as heavy metal ions is not often proportional to their $S_{\mathrm{BET}}$ values [16,32]. 
Table 1. Pore characteristics of the synthesized AC samples.

\begin{tabular}{|c|c|c|c|}
\hline \multirow{2}{*}{ Sample } & BET Surface Area & Pore Volume & Average Pore Size \\
\hline & $\left(m^{2} g^{-1}\right)$ & $\left(\mathrm{cm}^{3} \mathrm{~g}^{-1}\right)$ & $(\mathrm{nm})$ \\
\hline WAC & 792 & 0.34 & 1.74 \\
\hline ACZ1175 & 1757 & 1.02 & 2.34 \\
\hline ACK1075 & 1013 & 0.42 & 1.65 \\
\hline
\end{tabular}

Abbreviation: BET-Brunauer-Emmett-Teller.

Figure 3 indicates the pore size distributions of the AC samples selected. As can be seen, the main pore sizes of the three AC samples were approximately focused on $1.0 \mathrm{~nm}$. However, the maximum pore sizes exceeded $50 \mathrm{~nm}$. Small pore size and high pore volume could increase the $S_{\mathrm{BET}}$ values of the adsorbents. The adsorbent with high $S_{\mathrm{BET}}$ might favor dye adsorption. When the pore size is less than $2.0 \mathrm{~nm}$, it is difficult for a dye of high molecular weight to enter their micropore network. This might lead to lower adsorption capacity for the dye if the pore filling mechanism plays a dominant role in the adsorption process.

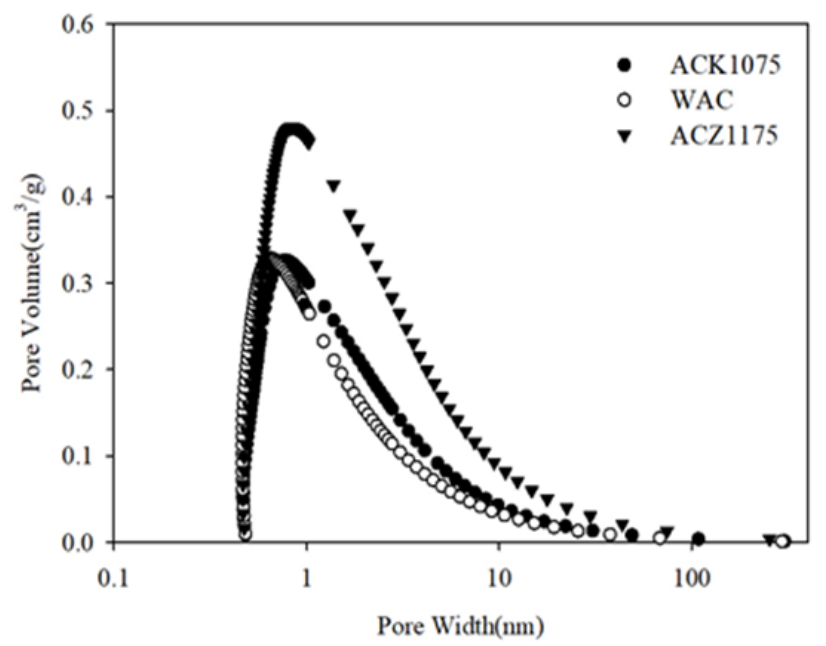

Figure 3. Pore size distribution of WAC, ACZ1175, and ACK1075.

The main functional groups on the adsorbent surface are a critical factor in determining the adsorptive amounts of the contaminants tested. Therefore, the FTIR spectra of WAC, ACK1075, and ACZ1175 are presented in Figure 4. It was found that the process of activation can lead to an evident increase in the number of functional groups. The bands at around $3700 \mathrm{~cm}^{-1}$ are attributed to $\mathrm{OH}$ group stretching vibrations. The potential functional groups include carboxylic acids, phenols, and alcohols. In addition, the presence of $\mathrm{C}=\mathrm{O}$ groups such as in carboxylic acid likely resulted in the formation of bands at around $1700 \mathrm{~cm}^{-1}$. Moreover, the observed bands at $1500-1600 \mathrm{~cm}^{-1}$ are ascribed to the vibration of aromatic $C=C$. Lastly, the identified bands in the range of $700-900 \mathrm{~cm}^{-1}$ are attributed to the groups of substituted aromatic rings.

Although the functional groups can determine the adsorption characteristics of the contaminants onto the adsorbents, the elemental compositions of the adsorbents yield further insight. Table 2 indicates the elemental compositions of the representative AC samples. Carbon was the primary element in the AC samples. The carbon contents of the representative AC samples exceeded $85 \%$, thereby corresponding to those of the other AC samples synthesized and reported in the literature [33,34]. The oxygen contents were in the range of $7 \%-14 \%$. These results imply the presence of oxygen-containing functional groups on the surfaces of the AC samples. According to the FTIR spectra, the $\mathrm{C}=\mathrm{O}$ and $\mathrm{OH}$ groups were the major oxygen-containing functionalities in this study. 


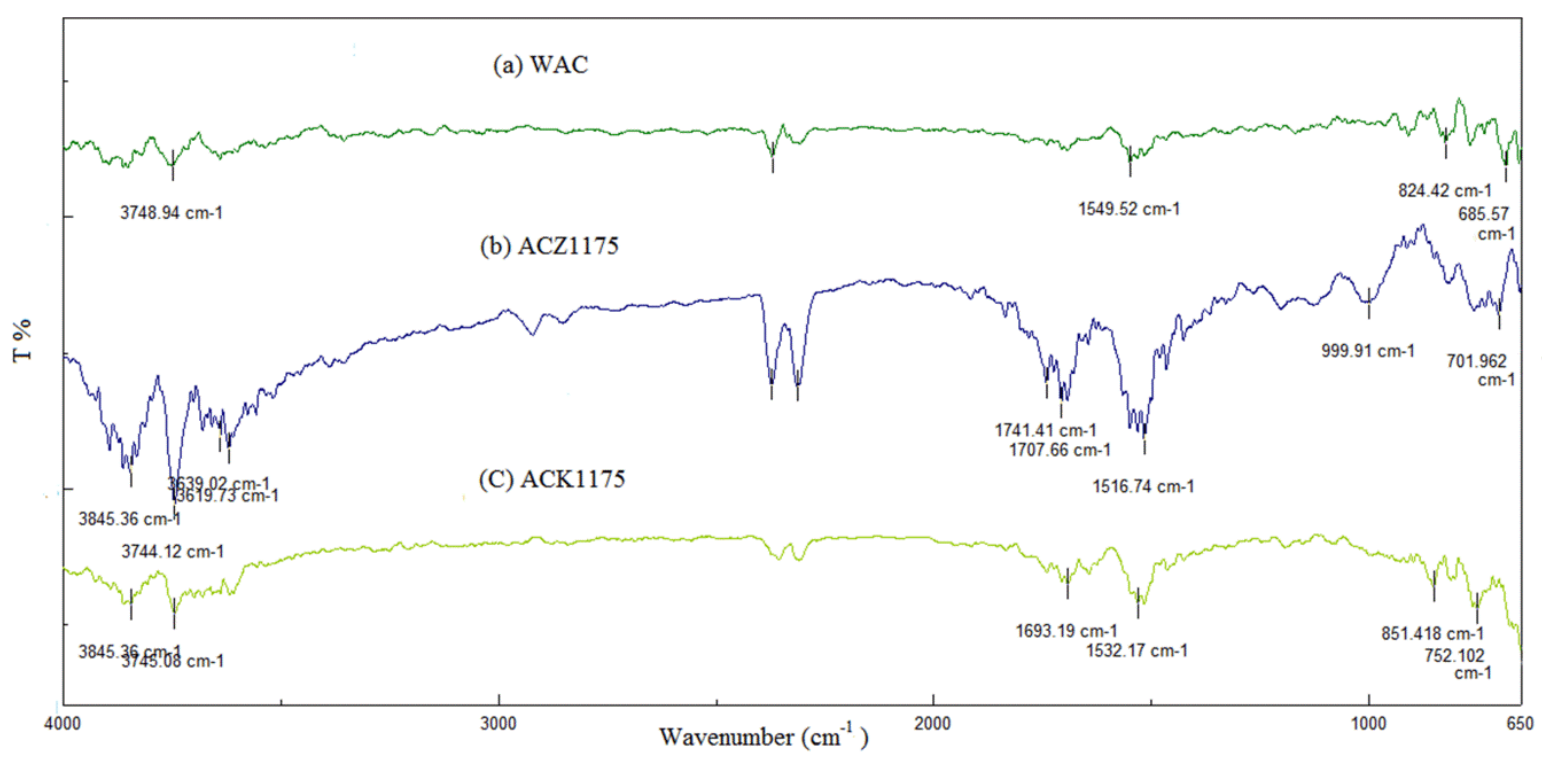

Figure 4. FTIR spectra of (a) WAC, (b) ACZ1175, and (c) ACK1075.

Table 2. Elemental compositions of the selected AC samples.

\begin{tabular}{cccccc}
\hline \multirow{2}{*}{ Sample } & \multicolumn{5}{c}{ Atomic Concentration of Elements by XPS (At\%) } \\
\cline { 2 - 6 } & $\mathbf{C}$ & $\mathbf{O}_{\mathbf{1 s}}$ & $\mathbf{K}$ & $\mathbf{Z n}$ & $\mathbf{C l}$ \\
\hline WAC & 90.31 & 9.69 & - & - & - \\
ACZ1175 & 91.32 & 7.55 & - & - & 0.17 \\
ACK1075 & 85.72 & 13.8 & 0.49 & - & - \\
\hline
\end{tabular}

Abbreviation: XPS—X-ray photoelectron spectroscopy.

The OFGs of all the AC samples, as determined by the Boehm titration method $[27,28]$, are provided in Table 3. The oxygen-containing functional groups of the activated samples were higher than those of WAC. This result is in agreement with the observations from the FTIR spectra. The process of activation can evidently enhance the adsorptive amounts of the contaminants tested. Of the AC samples, ACZ1175 and ACK1075 possessed more oxygen-containing functional groups than those of the others activated using either $\mathrm{ZnCl}_{2}$ or $\mathrm{K}_{2} \mathrm{CO}_{3}$. The amounts of oxygen-containing functional groups of the AC samples activated by $\mathrm{ZnCl}_{2}$ were slightly greater than those of the AC samples activated by $\mathrm{K}_{2} \mathrm{CO}_{3}$. However, the amount of phenolic functional group did not vary evidently with activation. In addition, significant changes in the quantities of carboxylic and alcoholic groups were found when the activating agent $\mathrm{ZnCl}_{2}$ was used. Moreover, the amounts of the oxygen-containing functional groups of the AC samples were only slightly altered by employing different ratios of $\mathrm{K}_{2} \mathrm{CO}_{3}$ to HTC. These results likely affected the adsorptive amounts of the contaminants tested.

Table 3. Oxygen-containing functional groups (OFGs) of the AC samples.

\begin{tabular}{ccccc}
\hline \multirow{2}{*}{ Sample } & \multicolumn{4}{c}{ Acidic Groups $(\mathbf{m m o l} / \mathbf{g})$} \\
\cline { 2 - 5 } & Carboxylic & Alcoholic & Phenolic & Total \\
\hline WAC & 0.54 & 0.72 & 0.38 & 1.64 \\
ACZ1075 & 0.83 & 0.82 & 0.40 & 2.05 \\
ACZ1100 & 0.94 & 0.84 & 0.41 & 2.19 \\
ACZ1125 & 1.11 & 0.97 & 0.42 & 2.50 \\
ACZ1175 & 1.21 & 1.04 & 0.45 & 2.70 \\
ACZ1200 & 1.08 & 0.92 & 0.44 & 2.44 \\
ACK1075 & 0.92 & 081 & 0.43 & 2.16 \\
ACK1100 & 0.88 & 0.90 & 0.37 & 2.15 \\
ACK1125 & 0.84 & 0.78 & 0.44 & 2.06 \\
ACK1175 & 0.81 & 0.88 & 0.36 & 2.05 \\
ACK1200 & 0.83 & 0.81 & 0.40 & 2.04 \\
\hline
\end{tabular}




\subsection{Adsorption Capacity of $M B, C d(I I)$, and $C u(I I)$ by $A C s$}

Figure 5 displays the adsorption isotherms of $\mathrm{MB}, \mathrm{Cd}(\mathrm{II})$, and $\mathrm{Cu}(\mathrm{II})$ for the selected $\mathrm{AC}$ samples. All curves exhibit a concave downward shape, representing the high affinity between the adsorbates and adsorbents. The target adsorbates were classified as typical cationic contaminants. Thus, ion exchange (or electrostatic force) was regarded as a potential adsorption mechanism based on the $\mathrm{COOH}$-group-rich surfaces of the adsorbents. This demonstrated that the process of activation can effectively enhance the adsorptive amounts of the cationic contaminants. As seen in Figure 5, the adsorptive amounts of the three adsorbates decreased in the following order: ACZ1175 > ACK1075 > WAC. The amounts adsorbed onto the selected adsorbents were proportional to their amounts of oxygen-containing groups. The results suggest that the amount of oxygen-containing groups was the primary factor in determining the adsorption of the cationic contaminants tested.

The MB adsorption capacities of all the ACs synthesized, as estimated from the Langmuir model, are listed in Table 4. The ACZ1175 and ACK1075 samples exhibited the highest MB adsorption capacities among all the AC samples activated using $\mathrm{ZnCl}_{2}$ and $\mathrm{K}_{2} \mathrm{CO}_{3}$, respectively. In Table 4, all the $R^{2}$ values are more than 0.95 . This indicated that the Langmuir model can be used to estimate the maximum adsorption capacities. The adsorptive amount of MB is proportional to the amount of OFGs.

Table 4. Methylene blue (MB) adsorption capacities of the AC samples synthesized through various processes of activation.

\begin{tabular}{|c|c|c|c|}
\hline \multirow[t]{2}{*}{ Sample } & $K_{\mathrm{L}}$ & $b$ & \multirow{2}{*}{$R^{2}$} \\
\hline & $\left(\mathrm{L} \mathrm{mg}^{-1}\right)$ & $\left(\mathrm{mg} \mathrm{g}^{-1}\right) /\left(\mathrm{mmol} \mathrm{g}^{-1}\right)$ & \\
\hline WAC & 0.0138 & $360 / 1.13$ & 0.995 \\
\hline ACZ1075 & 0.0117 & $503 / 1.57$ & 0.984 \\
\hline ACZ1100 & 0.0148 & $536 / 1.68$ & 0.993 \\
\hline ACZ1125 & 0.0219 & $569 / 1.78$ & 0.978 \\
\hline ACZ1175 & 0.0250 & $614 / 1.92$ & 0.985 \\
\hline ACZ1200 & 0.0863 & $576 / 1.80$ & 0.991 \\
\hline ACK1075 & 0.1112 & $516 / 1.61$ & 0.994 \\
\hline ACK1100 & 0.0910 & $509 / 1.59$ & 0.985 \\
\hline ACK1125 & 0.1236 & $494 / 1.54$ & 0.975 \\
\hline ACK1175 & 0.0986 & $493 / 1.54$ & 0.984 \\
\hline ACK1200 & 0.1032 & $499 / 1.56$ & 0.986 \\
\hline
\end{tabular}

The $\mathrm{Cd}(\mathrm{II})$ and $\mathrm{Cu}(\mathrm{II})$ adsorption capacities of all the ACs synthesized are presented in Tables 5 and 6, respectively. As can be seen, the AC samples synthesized demonstrated high adsorption capacities for $\mathrm{Cd}$ (II) and $\mathrm{Cu}(\mathrm{II})$. The ACZ1175 and ACK1075 samples exhibited the highest adsorption capacities among the samples activated using $\mathrm{ZnCl}_{2}$ and $\mathrm{K}_{2} \mathrm{CO}_{3}$, respectively. Thus, these results additionally demonstrated that the oxygen-containing functional groups were critical factors for adsorption on the surfaces of the AC samples. In addition, the adsorptive amounts of cationic metals on the AC samples activated by $\mathrm{ZnCl}_{2}$ increased with the ratio of the activating agent to HTC. When the ratio exceeded 1.75:1, the adsorptive amounts of the heavy metal ions began to drop. These results indicate that a high weight ratio of the activating agent to HTC could lead to a reduction in the adsorptive amounts of the contaminants, which can be primarily ascribed to the ability of the activating agent to destruct the properties of the carbonaceous materials. A similar result was presented in the literature [16]. However, high weight ratios of $\mathrm{K}_{2} \mathrm{CO}_{3}$ to HTC do not result in obvious changes in the adsorptive amounts of the metal ions tested. This result indicates that different activating agents exhibit diverse effects in the process of activation. 

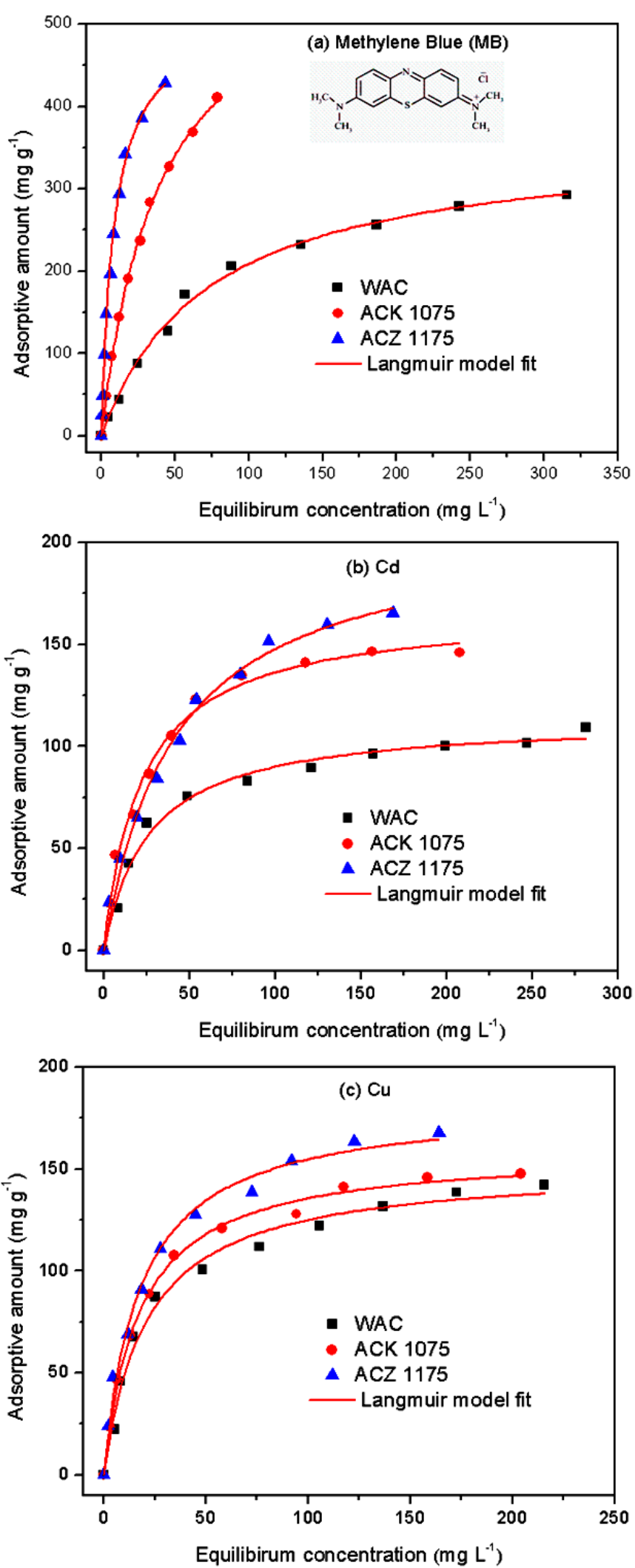

Figure 5. Isotherms for adsorption of (a) $\mathrm{MB}$, (b) $\mathrm{Cd}(\mathrm{II})$, and (c) $\mathrm{Cu}(\mathrm{II})$ onto WAC, $\mathrm{ACZ1175}$, and ACK1075. 
Table 5. $\mathrm{Cd}^{2+}$ adsorption capacities of the AC samples synthesized through various processes of activation.

\begin{tabular}{|c|c|c|c|}
\hline \multirow{2}{*}{ Sample } & $K_{\mathrm{L}}$ & $b$ & \multirow{2}{*}{$R^{2}$} \\
\hline & $\left(\mathrm{L} \mathrm{mg}^{-1}\right)$ & $\left(\mathrm{mg} \mathrm{g}^{-1}\right) /\left(\mathrm{mmol} \mathrm{g}^{-1}\right)$ & \\
\hline WAC & 0.037 & $113 / 1.01$ & 0.987 \\
\hline ACZ1075 & 0.042 & $156 / 1.39$ & 0.997 \\
\hline ACZ1100 & 0.048 & $164 / 1.46$ & 0.991 \\
\hline ACZ1125 & 0.014 & $182 / 1.63$ & 0.982 \\
\hline ACZ1175 & 0.024 & $208 / 1.86$ & 0.992 \\
\hline ACZ1200 & 0.018 & $174 / 1.55$ & 0.983 \\
\hline ACK1075 & 0.045 & $166 / 1.48$ & 0.992 \\
\hline ACK1100 & 0.045 & $159 / 1.42$ & 0.974 \\
\hline ACK1125 & 0.066 & $158 / 1.41$ & 0.976 \\
\hline ACK1175 & 0.075 & $164 / 1.46$ & 0.982 \\
\hline ACK1200 & 0.034 & $162 / 1.45$ & 0.984 \\
\hline
\end{tabular}

Table 6. $\mathrm{Cu}^{2+}$ adsorption capacities of the AC samples synthesized through various processes of activation.

\begin{tabular}{|c|c|c|c|}
\hline \multirow{2}{*}{ Sample } & $K_{\mathrm{L}}$ & $b$ & \multirow{2}{*}{$R^{2}$} \\
\hline & $\left(\mathrm{L} \mathrm{mg}^{-1}\right)$ & $\left(\mathrm{mg} \mathrm{g}^{-1}\right) /\left(\mathrm{mmol} \mathrm{g}^{-1}\right)$ & \\
\hline WAC & 0.048 & $151 / 2.30$ & 0.989 \\
\hline ACZ1075 & 0.031 & $158 / 2.49$ & 0.966 \\
\hline ACZ1100 & 0.041 & $162 / 2.55$ & 0.967 \\
\hline ACZ1125 & 0.048 & $172 / 2.71$ & 0.968 \\
\hline ACZ1175 & 0.056 & $182 / 2.87$ & 0.991 \\
\hline ACZ1200 & 0.062 & $176 / 2.77$ & 0.982 \\
\hline ACK1075 & 0.057 & $159 / 2.48$ & 0.991 \\
\hline ACK1100 & 0.044 & $156 / 2.46$ & 0.988 \\
\hline ACK1125 & 0.037 & $154 / 2.43$ & 0.976 \\
\hline ACK1175 & 0.047 & $155 / 2.44$ & 0.992 \\
\hline ACK1200 & 0.031 & $152 / 2.39$ & 0.978 \\
\hline
\end{tabular}

\subsection{Comparison of Adsorption Mechanisms}

Tables 4-6 present the adsorptive amounts of the contaminants in millimoles per gram. It can be seen that the adsorptive amounts on the millimole-per-gram basis trend down approximately in the following order: $\mathrm{Cu}(\mathrm{II})>\mathrm{MB}>\mathrm{Cd}(\mathrm{II})$. This is probably a result of different adsorption mechanisms, indicating that ion exchange was not the sole mechanism promoting adsorption. The driving factors of the adsorption of organic dyes onto the AC samples have been classified as (i) van der Waals forces, (ii) pore filling, (iii) ion exchange, (iv) hydrogen bonding, (v) $\pi-\pi$ interaction, and (vi) $n-\pi$ interaction [35,36]. Although the $\pi-\pi$ and $n-\pi$ interactions could potentially occur according to the elemental compositions of the adsorbents and the chemical structure of $\mathrm{MB}$, the two interactions are deemed less important than the other mechanisms [37]. The influence of van der Waals forces mainly correlates with the $S_{\mathrm{BET}}$ values of the adsorbents. Pore filling occurs easily in porous carbonaceous adsorbents. The AC samples synthesized possess high values of $S_{\mathrm{BET}}$ and pore volume. Hence, van der Waals forces and pore filling are regarded as the potential adsorption mechanisms. However, $\mathrm{MB}$ is a high-molecular-weight dye. It may be difficult for MB to enter the inner pores of the AC samples, which reduces its adsorptive amount.

The adsorbate $\mathrm{MB}$ is an aromatic dye with the molecular formula $\mathrm{C}_{16} \mathrm{H}_{18} \mathrm{ClN}_{3} \mathrm{~S}$. The $\mathrm{N}$ atoms could generate hydrogen bonding with the oxygen atoms on the surfaces of the ACs. As a result, hydrogen bonding is a potential adsorption mechanism of MB onto AC. Moreover, the surface of $\mathrm{AC}$ is rich in acidic groups and could attract the MB molecules by means of ion exchange. The two adsorption mechanisms were highly correlated with the total amount of oxygen-containing functional 
groups and were regarded as potential adsorption mechanisms. Nonetheless, pore size could still affect the adsorption mechanism of $\mathrm{MB}$ onto the porous materials.

Major mechanisms for the adsorption of cationic metals onto the AC samples, in general, include ion exchange and complexation reaction. These two adsorption mechanisms correlate to a certain extent with the amount of oxygen-containing functional groups as well. Therefore, the AC samples rich in oxygen-containing functional groups could exhibit a relatively high adsorptive capacity towards certain heavy metal ions. As shown in Tables 5 and 6, the adsorptive amounts (mmol/g) of $\mathrm{Cu}$ (II) were higher than those of $\mathrm{Cd}(\mathrm{II})$, which implies that the complexation reaction between the metal ions and AC samples might have been a rather important underlying mechanism. This is because ion exchange increases with ion radius, but the ion radius of $\mathrm{Cd}^{2+}$ is larger than that of $\mathrm{Cu}^{2+}(0.97 \AA$ vs. $0.73 \AA)$, so if ion exchange was the sole adsorption mechanism, the adsorptive amount in millimoles per gram of $\mathrm{Cd}^{2+}$ should have been higher than that of $\mathrm{Cu}^{2+}$. However, the trend of ionic radii was in opposite direction of the trend of the adsorption capacity in this study. On the other hand, it is known that $\mathrm{Cu}$ (II) can easily form complexes with the oxygen moiety on the AC surface. Hence, the higher adsorptive amount of $\mathrm{Cu}$ (II) than that of $\mathrm{Cd}$ (II) might in large part have been due to the complexation reaction.

When the adsorptive amount of MB was compared with that of $\mathrm{Cu}(\mathrm{II})$ and $\mathrm{Cd}(\mathrm{II})$ on the basis of millimoles per gram, the results further indicated that the adsorption of $\mathrm{MB}$ onto the AC samples might have proceeded via ion exchange and other mechanisms. This comes from the rationale that ion exchange was the primary mechanism for the adsorption of $\mathrm{Cd}(\mathrm{II})$ onto the $\mathrm{AC}$ samples, and if it were assumed to be the primary pathway resulting in the $\mathrm{AC}-\mathrm{MB}$ adsorptive interaction, the adsorptive amounts of $\mathrm{MB}$ should have been approximately twice those of $\mathrm{Cu}(\mathrm{II})$ and $\mathrm{Cd}(\mathrm{II})$. However, the adsorptive amounts of $\mathrm{MB}$ were slightly higher than those of $\mathrm{Cd}(\mathrm{II})$. This again implies that hydrogen bonding, van der Waals forces, and other mechanisms might have all been involved in the process of $\mathrm{MB}$ adsorption on the AC samples, but they played a smaller role.

Additionally, the maximum adsorption capacities of MB and heavy metals on the ACs compared with carbonaceous materials reported in the literature are listed in Table 7 [38-43]. It can be seen that the adsorption capacities of the ACs prepared in this work are equally good or even superior to those reported in other studies. Therefore, teak-sawdust-based ACs (or biomass-based carbonaceous sorbents in general) prepared via a coupled hydrothermal carbonization/chemical activation process may have high application potential for wastewater treatments. 
Table 7. Comparisons of the adsorption capacity of various adsorbents for methylene blue and heavy metals.

\begin{tabular}{|c|c|c|c|c|c|c|}
\hline Raw Material & Process & $\begin{array}{c}\text { Production } \\
\text { Temperature/Time }\end{array}$ & $\begin{array}{c}\text { Target } \\
\text { Sorbate }\end{array}$ & $\begin{array}{l}\text { Adsorption } \\
\text { Mechanism }\end{array}$ & $\begin{array}{c}\text { Adsorption Capacity } \\
Q^{0}{ }_{\max } \\
\end{array}$ & Reference \\
\hline \multirow[t]{2}{*}{ Factory-rejected tea (FTR) } & $\begin{array}{l}\text { 1st: Hydrothermal } \\
\text { carbonization (HTC) }\end{array}$ & $200^{\circ} \mathrm{C}, 5 \mathrm{~h}$ & \multirow[t]{2}{*}{$\begin{array}{l}\text { Methylene } \\
\text { blue (MB) }\end{array}$} & \multirow{2}{*}{$\begin{array}{l}\text { The hydrochar-to-NaOH ratio plays a role in the surface } \\
\text { structure of AC. Provided the best textural characteristics } \\
\text { with diverse functional groups. }\end{array}$} & \multirow[t]{2}{*}{$487.4 \mathrm{mg} / \mathrm{g}$} & \multirow[t]{2}{*}{ [40] } \\
\hline & 2nd: Impregnated by $\mathrm{NaOH}$ & $800^{\circ} \mathrm{C}, 1 \mathrm{~h}$ & & & & \\
\hline \multirow[b]{2}{*}{ Bamboo } & $\begin{array}{l}\text { 1st: Hydrothermal } \\
\text { carbonization (deionized water } \\
\text { and } \mathrm{HCl} 1 \mathrm{M}) \text {. }\end{array}$ & $200^{\circ} \mathrm{C}, 24 \mathrm{~h}$ & \multirow{2}{*}{$\begin{array}{l}\text { Methylene } \\
\text { blue (MB) }\end{array}$} & \multirow{2}{*}{$\begin{array}{l}\text { The surface area and pore volume of hydrochar produced in } \\
\text { acid medium was large and } \mathrm{NaOH} \text { treatment of as-produced } \\
\text { hydrochar can enhance the oxygen-containing functional } \\
\text { groups on its surface. }\end{array}$} & \multirow{2}{*}{$\begin{array}{c}655.7 \mathrm{mg} / \mathrm{g} \text { of modified hydrochar } \\
\text { compared to } 268.9 \mathrm{mg} / \mathrm{g} \text { of original } \\
\text { hydrochar }\end{array}$} & \multirow[b]{2}{*}{ [43] } \\
\hline & $\begin{array}{l}\text { 2nd: Mixture between } \\
1 \mathrm{~g} \text { of hydrochar samples, } \\
0.25 \mathrm{M} 100 \mathrm{~mL} \mathrm{NaOH}\end{array}$ & $\begin{array}{l}\text { Room temperature, } \\
1 \mathrm{~h}\end{array}$ & & & & \\
\hline \multirow{2}{*}{$\begin{array}{l}\text { Vegetables such as prickly pear } \\
\text { peels-CarTuna, white sapote } \\
\text { seeds-CarZapQ, and broccoli } \\
\text { stems-CarBrocQ. }\end{array}$} & $\begin{array}{l}\text { 1st: The impregnation ratio of } \\
\text { vegetable residue/ } \mathrm{H}_{3} \mathrm{PO}_{4} \\
\qquad(\mathrm{w} / \mathrm{w}) .\end{array}$ & $\begin{array}{l}\text { Room temperature, } \\
24 \mathrm{~h}\end{array}$ & \multirow{2}{*}{$\begin{array}{l}\text { Methylene } \\
\text { blue (MB) }\end{array}$} & \multirow{2}{*}{$\begin{array}{l}\text { Introduction of a large specific surface area and high total } \\
\text { pore volume with average pore size. Additionally, the } \\
\text { presence of anionic and cationic functional groups, found by } \\
\text { means of FTIR, confers the carbons the ability to adsorb MB. }\end{array}$} & \multirow{2}{*}{$\begin{array}{l}\text { Maximum adsorption capacities of } \\
\text { CarZapQ, CarTunaQ, and CarBrocQ } \\
\text { for MB were 277.8, 416.7, and } \\
500.0 \mathrm{mg} / \mathrm{g} \text {, respectively. }\end{array}$} & \multirow[t]{2}{*}{ [41] } \\
\hline & 2nd: Pyrolysis & $400^{\circ} \mathrm{C}, 3 \mathrm{~h}$ & & & & \\
\hline \multirow{3}{*}{ Teak (Tectona grandis) sawdust } & 1st: Teak sawdust-hydrochar & $190^{\circ} \mathrm{C}, 24 \mathrm{~h}$ & $\begin{array}{l}\text { Methylene } \\
\text { blue (MB) }\end{array}$ & \multirow{3}{*}{$\begin{array}{l}\text { Increasing amount of oxygen-containing functional groups is } \\
\text { regarded as an important factor in determining the } \\
\text { adsorptive amounts. Electrostatic force is the primary } \\
\text { adsorption mechanism for the contaminants tested. } \\
\text { The complexation reaction is a vital adsorption mechanism } \\
\text { for } \mathrm{Cu}^{2+} \text {. Other mechanisms are less important in the } \\
\text { adsorption of } \mathrm{MB} \text { and } \mathrm{Cd}^{2+} \text {. }\end{array}$} & $\begin{array}{l}\text { ACZ1175: } 614.0 \mathrm{mg} / \mathrm{g} \\
\text { ACK1075: } 516.0 \mathrm{mg} / \mathrm{g}\end{array}$ & This study \\
\hline & \multirow{2}{*}{$\begin{array}{l}\text { 2nd: } \mathrm{AC} \text { samples synthesized } \\
\text { by chemical activation } \mathrm{K}_{2} \mathrm{CO}_{3} \\
\text { (ACK1075) or } \mathrm{ZnCl} \mathrm{l}_{2}(\mathrm{ACZ1175)} \\
\text { in various weight ratios. }\end{array}$} & \multirow[b]{2}{*}{$800^{\circ} \mathrm{C}, 4 \mathrm{~h}$} & $\begin{array}{l}\text { Cadmium } \\
\left(\mathrm{Cd}^{2+}\right)\end{array}$ & & $\begin{array}{l}208.0 \mathrm{mg} / \mathrm{g} \text { for ACZ1175 and } \\
166.0 \mathrm{mg} / \mathrm{g} \text { for ACK1075 }\end{array}$ & This study \\
\hline & & & $\begin{array}{l}\text { Copper } \\
\left(\mathrm{Cu}^{2+}\right)\end{array}$ & & $\begin{array}{l}182.0 \mathrm{mg} / \mathrm{g} \text { for ACZ1175 and } \\
159.0 \mathrm{mg} / \mathrm{g} \text { for ACK1075 }\end{array}$ & This study \\
\hline \multirow[b]{2}{*}{ Coconut shells } & $\begin{array}{l}\text { 1st: Hydrothermal } \\
\text { carbonization }\end{array}$ & $200^{\circ} \mathrm{C}, 2 \mathrm{~h}$ & \multirow[b]{2}{*}{$\begin{array}{l}\text { Methylene } \\
\text { blue (MB) }\end{array}$} & \multirow{2}{*}{$\begin{array}{l}\text { Presence of carbon-rich hydrochar with a high yield of } 77 \% \\
\text { and an oxygen-group-enriched structure was produced } \\
\text { through hydrothermal carbonization }\end{array}$} & \multirow[b]{2}{*}{$200.0 \mathrm{mg} / \mathrm{g}$} & \multirow[b]{2}{*}{ [42] } \\
\hline & $\begin{array}{l}\text { 2nd: Impregnated by } \mathrm{NaOH} \\
\text { for } 4 \text { h. Activated by heating in } \\
\text { a horizontal tubular } \\
\text { stainless-steel reactor. }\end{array}$ & $600^{\circ} \mathrm{C}, 1 \mathrm{~h}$ & & & & \\
\hline \multirow{2}{*}{$\begin{array}{l}\text { Sawdust, wheat straw, and } \\
\text { corn stalk }\end{array}$} & 1st: HTC & $200^{\circ} \mathrm{C}, 20 \mathrm{~h}$ & \multirow{2}{*}{$\begin{array}{l}\text { Cadmium } \\
\left(\mathrm{Cd}^{2+}\right)\end{array}$} & \multirow{2}{*}{$\begin{array}{l}\text { KOH modification of hydrochars might have increased the } \\
\text { aromatic and oxygen-containing functional groups, such as } \\
\text { carboxyl groups. }\end{array}$} & \multirow{2}{*}{$\begin{array}{l}\text { Increasing the sorption capacity of } \\
\qquad \mathrm{Cd}(30.4-40.7 \mathrm{mg} / \mathrm{g})\end{array}$} & \multirow[b]{2}{*}{ [39] } \\
\hline & $\begin{array}{l}\text { 2nd: Impregnated by } \\
500 \mathrm{~mL} \text { of } 2 \mathrm{M} \mathrm{KOH}\end{array}$ & $\begin{array}{c}\text { Room temperature, } \\
1 \mathrm{~h}\end{array}$ & & & & \\
\hline \multirow{2}{*}{ Pitch-based carbon fibers } & $\begin{array}{c}\text { 1st: Pyrolysis } \\
\text { (denoted as ACFs) }\end{array}$ & $900^{\circ} \mathrm{C}, 0.5 \mathrm{~h}$ & \multirow[t]{2}{*}{ Copper $\left(\mathrm{Cu}^{2+}\right)$} & \multirow{2}{*}{$\begin{array}{l}\text { Increasing the formation of functional groups without } \\
\text { damage to the fiber surface. The adsorption capacity of } \mathrm{Cu}^{2+} \\
\text { and } \mathrm{Ni}^{2+} \text { is mainly influenced by the quantity of lactone } \\
\text { groups on the carbon surface at } \mathrm{pH}<\mathrm{pHzpc} \text { and by the } \\
\text { amount of acidic functional groups at } \mathrm{pH}>\mathrm{pHzpc} \text {. }\end{array}$} & \multirow{2}{*}{$\begin{array}{l}32.2 \text { and } 11.2 \mathrm{mg} / \mathrm{g} \text { of } \mathrm{ACF} 15-\mathrm{HNO}_{3} \\
\text { for } \mathrm{Cu}^{2+} \text { and Ni }{ }^{2+}, \text { respectively. } \\
26.8 \text { and } 10.2 \mathrm{mg} / \mathrm{g} \text { of ACF15-NaOH } \\
\text { for } \mathrm{Cu}^{2+} \text { and } \mathrm{Ni}^{2+} \text {, respectively }\end{array}$} & \multirow{2}{*}{ [38] } \\
\hline & $\begin{array}{l}\text { 2nd: Modification of ACFs } \\
\text { with } \mathrm{HNO}_{3}(1 \mathrm{M}) \text { and } \\
\mathrm{NaOH}(1 \mathrm{M})\end{array}$ & $\begin{array}{l}\text { Boiling temperature, } \\
\qquad 2 \mathrm{~h} \text {. }\end{array}$ & & & & \\
\hline
\end{tabular}




\section{Conclusions}

In the present study, teak (T. grandis) sawdust was used to synthesize ACs through a two-step process: hydrothermal carbonization, followed by chemical activation with $\mathrm{ZnCl}_{2}$ or $\mathrm{K}_{2} \mathrm{CO}_{3}$ at various concentrations. The AC samples produced were characterized through the SEM, an $S_{\mathrm{BET}}$ analyzer, FTIR, $X P S$, and titration to determine the acidic functional groups. The results demonstrated that the synthetic AC samples possessed high $S_{\mathrm{BET}}$ and were rich in oxygen-containing functional groups, which was favorable to the adsorption of cationic contaminants. The adsorbent generated from $\mathrm{ZnCl}_{2}$-activated HTC, with HTC and $\mathrm{ZnCl}_{2}$ in the weight ratio of 1.75:1.0, exhibited the highest adsorption capacities for $\mathrm{MB}, \mathrm{Cd}(\mathrm{II})$, and $\mathrm{Cu}(\mathrm{II})$. The maximum adsorption capacities of $\mathrm{ACZ1175}$ for $\mathrm{MB}, \mathrm{Cd}(\mathrm{II})$, and $\mathrm{Cu}(\mathrm{II})$ were 614,208 , and $182 \mathrm{mg} / \mathrm{g}$, respectively. Activation of $\mathrm{K}_{2} \mathrm{CO}_{3}$ with various concentrations resulted in little variation in the adsorptive amounts of the AC samples for the various contaminants tested. The AC samples prepared from the teak sawdust-hydrochar via chemical activation using $\mathrm{ZnCl}_{2}$ and $\mathrm{K}_{2} \mathrm{CO}_{3}$ exhibited high adsorptive amounts for cationic contaminants. Ion exchange was the primary adsorption mechanism of the contaminants tested. Thus, the amount of oxygen-containing functional groups was the critical factor in determining the adsorptive amounts of the contaminants tested. The complexation reaction was a relatively important mechanism for the adsorption of $\mathrm{Cu}$ (II) onto the AC samples. Compared with ion exchange, other mechanisms were determined to be less important in the process of $\mathrm{MB}$ and $\mathrm{Cd}(\mathrm{II})$ adsorption in this study. Together, these results demonstrate that teak-sawdust-based ACs (or biomass-based carbonaceous sorbents in general) prepared via a coupled hydrothermal carbonization/chemical activation process can be potentially applied in the wastewater treatment process.

Author Contributions: H.N.T. and H.-P.C. conceived the study and designed the experiments. H.D.N. and H.N.T. performed the experiments. H.D.N. and H.-P.C. analyzed and interpreted data and wrote the manuscript. C.-C.L. and H.-P.C. contributed to data interpretation, obtained funding, and edited the manuscript.

Funding: This work was supported by the Taiwan Ministry of Science and Technology.

Acknowledgments: We thank all of our laboratory colleagues for their constant support. We also thank the comments and suggestions from the reviewers, which greatly improved this manuscript.

Conflicts of Interest: The authors declare no conflict of interest.

\section{References}

1. Tian, F.; Wu, Z.; Chen, Q.; Yan, Y.; Cravotto, G.; Wu, Z. Microwave-induced crystallization of $\mathrm{AC} / \mathrm{TiO}_{2}$ for improving the performance of rhodamine B dye degradation. Appl. Surf. Sci. 2015, 351, 104-112. [CrossRef]

2. Kim, S.; Chu, K.H.; Al-Hamadani, Y.A.; Park, C.M.; Jang, M.; Kim, D.-H.; Yu, M.; Heo, J.; Yoon, Y. Removal of contaminants of emerging concern by membranes in water and wastewater: A review. Chem. Eng. J. 2018, 335, 896-914. [CrossRef]

3. Tran, H.N.; Chao, H.-P.; You, S.-J. Activated carbons from golden shower upon different chemical activation methods: Synthesis and characterizations. Adsorpt. Sci. Technol. 2018, 36, 95-113. [CrossRef]

4. Li, C.; Chen, G.; Sun, J.; Rao, J.; Han, Z.; Hu, Y.; Xing, W.; Zhang, C. Doping effect of phosphate in $\mathrm{Bi}_{2} \mathrm{WO}_{6}$ and universal improved photocatalytic activity for removing various pollutants in water. Appl. Catal. $B$ Environ. 2016, 188, 39-47. [CrossRef]

5. Chen, X.; Wu, Z.; Liu, D.; Gao, Z. Preparation of ZnO photocatalyst for the efficient and rapid photocatalytic degradation of azo dyes. Nanoscale Res. Lett. 2017, 12, 143. [CrossRef]

6. Kumar, R.; Kumar, G.; Umar, A. ZnO nano-mushrooms for photocatalytic degradation of methyl orange. Mater. Lett. 2013, 97, 100-103. [CrossRef]

7. Liang, R.; Jing, F.; Shen, L.; Qin, N.; Wu, L. MIL-53 (Fe) as a highly efficient bifunctional photocatalyst for the simultaneous reduction of $\mathrm{Cr}(\mathrm{VI})$ and oxidation of dyes. J. Hazard. Mater. 2015, 287, 364-372. [CrossRef]

8. Liu, G.; Zhang, Y.; Xu, L.; Xu, B.; Li, F. A PW 12/ $\mathrm{Bi}_{2} \mathrm{WO}_{6}$ composite photocatalyst for enhanced visible light photocatalytic degradation of organic dye pollutants. New J. Chem. 2019, 43, 3469-3475. [CrossRef]

9. De Gisi, S.; Lofrano, G.; Grassi, M.; Notarnicola, M. Characteristics and adsorption capacities of low-cost sorbents for wastewater treatment: A review. Sustain. Mater. Technol. 2016, 9, 10-40. [CrossRef] 
10. Jung, C.; Park, J.; Lim, K.H.; Park, S.; Heo, J.; Her, N.; Oh, J.; Yun, S.; Yoon, Y. Adsorption of selected endocrine disrupting compounds and pharmaceuticals on activated biochars. J. Hazard. Mater. 2013, 263, 702-710. [CrossRef]

11. Lima, E.C. Removal of emerging contaminants from the environment by adsorption. Ecotoxicol. Environ. Saf. 2018, 150, 1-17.

12. Ren, X.; Chen, C.; Nagatsu, M.; Wang, X. Carbon nanotubes as adsorbents in environmental pollution management: A review. Chem. Eng. J. 2011, 170, 395-410. [CrossRef]

13. Bhatnagar, A.; Anastopoulos, I. Adsorptive removal of bisphenol A (BPA) from aqueous solution: A review. Chemosphere 2017, 168, 885-902. [CrossRef]

14. Tran, H.N.; Wang, Y.-F.; You, S.-J.; Chao, H.-P. Insights into the mechanism of cationic dye adsorption on activated charcoal: The importance of $\pi-\pi$ interactions. Process Saf. Environ. Prot. 2017, 107, 168-180. [CrossRef]

15. Tran, H.N.; You, S.-J.; Chao, H.-P. Fast and efficient adsorption of methylene green 5 on activated carbon prepared from new chemical activation method. J. Environ. Manag. 2017, 188, 322-336. [CrossRef]

16. Huang, F.-C.; Lee, C.-K.; Han, Y.-L.; Chao, W.-C.; Chao, H.-P. Preparation of activated carbon using micro-nano carbon spheres through chemical activation. J. Taiwan Inst. Chem. Eng. 2014, 45, 2805-2812. [CrossRef]

17. Güzel, F.; Sayğılı, H.; Sayğılı, G.A.; Koyuncu, F. Elimination of anionic dye by using nanoporous carbon prepared from an industrial biowaste. J. Mol. Liq. 2014, 194, 130-140. [CrossRef]

18. Libra, J.A.; Ro, K.S.; Kammann, C.; Funke, A.; Berge, N.D.; Neubauer, Y.; Titirici, M.-M.; Fühner, C.; Bens, O.; Kern, J.; et al. Hydrothermal carbonization of biomass residuals: A comparative review of the chemistry, processes and applications of wet and dry pyrolysis. Biofuels 2011, 2, 71-106. [CrossRef]

19. Pelekani, C.; Snoeyink, V.L. Competitive adsorption between atrazine and methylene blue on activated carbon: The importance of pore size distribution. Carbon 2000, 38, 1423-1436. [CrossRef]

20. Sun, L.; Wan, S.; Luo, W. Biochars prepared from anaerobic digestion residue, palm bark, and eucalyptus for adsorption of cationic methylene blue dye: Characterization, equilibrium, and kinetic studies. Bioresour. Technol. 2013, 140, 406-413. [CrossRef]

21. Xue, Y.; Gao, B.; Yao, Y.; Inyang, M.; Zhang, M.; Zimmerman, A.R.; Ro, K.S. Hydrogen peroxide modification enhances the ability of biochar (hydrochar) produced from hydrothermal carbonization of peanut hull to remove aqueous heavy metals: Batch and column tests. Chem. Eng. J. 2012, 200, 673-680. [CrossRef]

22. Jagtoyen, M.; Thwaites, M.; Stencel, J.; McEnaney, B.; Derbyshire, F. Adsorbent carbon synthesis from coals by phosphoric acid activation. Carbon 1992, 30, 1089-1096. [CrossRef]

23. Zhang, T.; Walawender, W.P.; Fan, L.; Fan, M.; Daugaard, D.; Brown, R. Preparation of activated carbon from forest and agricultural residues through $\mathrm{CO}_{2}$ activation. Chem. Eng. J. 2004, 105, 53-59. [CrossRef]

24. Fang, J.; Zhan, L.; Ok, Y.S.; Gao, B. Minireview of potential applications of hydrochar derived from hydrothermal carbonization of biomass. J. Ind. Eng. Chem. 2018, 57, 15-21. [CrossRef]

25. Sun, Y.; Gao, B.; Yao, Y.; Fang, J.; Zhang, M.; Zhou, Y.; Chen, H.; Yang, L. Effects of feedstock type, production method, and pyrolysis temperature on biochar and hydrochar properties. Chem. Eng. J. 2014, 240, 574-578. [CrossRef]

26. Tran, H.N.; Lee, C.-K.; Nguyen, T.V.; Chao, H.-P. Saccharide-derived microporous spherical biochar prepared from hydrothermal carbonization and different pyrolysis temperatures: Synthesis, characterization, and application in water treatment. Environ. Technol. 2018, 39, 2747-2760. [CrossRef]

27. Boehm, H.P. Chemical identification of surface groups. Adv. Catal. 1966, 16, 179-274.

28. Tsechansky, L.; Graber, E.R. Methodological limitations to determining acidic groups at biochar surfaces via the Boehm titration. Carbon 2014, 66, 730-733. [CrossRef]

29. Langmuir, I. The adsorption of gases on plane surfaces of glass, mica and platinum. J. Am. Chem. Soc. 1918, 40, 1361-1403. [CrossRef]

30. Sajjadi, S.-A.; Mohammadzadeh, A.; Tran, H.N.; Anastopoulos, I.; Dotto, G.L.; Lopičić, Z.R.; Sivamani, S.; Rahmani-Sani, A.; Ivanets, A.; Hosseini-Bandegharaei, A. Efficient mercury removal from wastewater by pistachio wood wastes-derived activated carbon prepared by chemical activation using a novel activating agent. J. Environ. Manag. 2018, 223, 1001-1009. [CrossRef] 
31. Sajjadi, S.-A.; Meknati, A.; Lima, E.C.; Dotto, G.L.; Mendoza-Castillo, D.I.; Anastopoulos, I.; Alakhras, F.; Unuabonah, E.I.; Singh, P.; Hosseini-Bandegharaei, A. A novel route for preparation of chemically activated carbon from pistachio wood for highly efficient $\mathrm{Pb}$ (II) sorption. J. Environ. Manag. 2019, 236, 34-44. [CrossRef]

32. Raymundo-Pinero, E.; Azais, P.; Cacciaguerra, T.; Cazorla-Amorós, D.; Linares-Solano, A.; Béguin, F. KOH and $\mathrm{NaOH}$ activation mechanisms of multiwalled carbon nanotubes with different structural organisation. Carbon 2005, 43, 786-795. [CrossRef]

33. Bouhamed, F.; Elouear, Z.; Bouzid, J. Adsorptive removal of copper (II) from aqueous solutions on activated carbon prepared from Tunisian date stones: Equilibrium, kinetics and thermodynamics. J. Taiwan Inst. Chem. Eng. 2012, 43, 741-749. [CrossRef]

34. Ozdemir, I.; Şahin, M.; Orhan, R.; Erdem, M. Preparation and characterization of activated carbon from grape stalk by zinc chloride activation. Fuel Process. Technol. 2014, 125, 200-206. [CrossRef]

35. Anjum, H.; Johari, K.; Appusamy, A.; Gnanasundaram, N.; Thanabalan, M. Surface modification and characterization of carbonaceous adsorbents for the efficient removal of oil pollutants. J. Hazard. Mater. 2019, 379, 120673. [CrossRef]

36. Tran, H.N.; You, S.-J.; Nguyen, T.V.; Chao, H.-P. Insight into the adsorption mechanism of cationic dye onto biosorbents derived from agricultural wastes. Chem. Eng. Commun. 2017, 204, 1020-1036. [CrossRef]

37. Tran, H.N.; You, S.-J.; Chao, H.-P. Insight into adsorption mechanism of cationic dye onto agricultural residues-derived hydrochars: Negligible role of $\pi-\pi$ interaction. Korean J. Chem. Eng. 2017, 34, 1708-1720. [CrossRef]

38. Shim, J.-W.; Park, S.-J.; Ryu, S.-K. Effect of modification with $\mathrm{HNO}_{3}$ and $\mathrm{NaOH}$ on metal adsorption by pitch-based activated carbon fibers. Carbon 2001, 39, 1635-1642. [CrossRef]

39. Sun, K.; Tang, J.; Gong, Y.; Zhang, H. Characterization of potassium hydroxide (KOH) modified hydrochars from different feedstocks for enhanced removal of heavy metals from water. Environ. Sci. Pollut. Res. 2015, 22, 16640-16651. [CrossRef]

40. Islam, M.A.; Benhouria, A.; Asif, M.; Hameed, B.H. Methylene blue adsorption on factory-rejected tea activated carbon prepared by conjunction of hydrothermal carbonization and sodium hydroxide activation processes. J. Taiwan Inst. Chem. Eng. 2015, 52, 57-64. [CrossRef]

41. Peláez-Cid, A.-A.; Herrera-González, A.-M.; Salazar-Villanueva, M.; Bautista-Hernández, A. Elimination of textile dyes using activated carbons prepared from vegetable residues and their characterization. J. Environ. Manag. 2016, 181, 269-278. [CrossRef]

42. Islam, M.A.; Ahmed, M.J.; Khanday, W.A.; Asif, M.; Hameed, B.H. Mesoporous activated coconut shell-derived hydrochar prepared via hydrothermal carbonization-NaOH activation for methylene blue adsorption. J. Environ. Manag. 2017, 203, 237-244. [CrossRef]

43. Qian, W.-C.; Luo, X.-P.; Wang, X.; Guo, M.; Li, B. Removal of methylene blue from aqueous solution by modified bamboo hydrochar. Ecotoxicol. Environ. Saf. 2018, 157, 300-306. [CrossRef]

(C) 2019 by the authors. Licensee MDPI, Basel, Switzerland. This article is an open access article distributed under the terms and conditions of the Creative Commons Attribution (CC BY) license (http://creativecommons.org/licenses/by/4.0/). 